\title{
DEVELOPMENT OF SUSTAINED RELEASE ALOGLIPTIN TABLETS USING A MULTIPARTICULATES SYSTEM MADE OF BENTONITE
}

\author{
RASHAD M. KAOUD ${ }^{1}$, ALHAMZA HOSHI KHALAF², JAMAL ALYOUSSEF ALKRAD ${ }^{2 *}$
}

1Pharmacy Department, Ashur University College, Bagdad, Iraq, ${ }^{2}$ Faculty of Pharmacy, Isra University, P0 Box 22 and 23, Amman, Jordan *Email: jamal.alkrad@iu.edu.jo

Received: 29 Dec 2020, Revised and Accepted: 13 Feb 2021

\begin{abstract}
Objective: This study was designed to evaluate the use of bentonite in the formulation of sustained-release tablets containing alogliptin benzoate after granulation.

Methods: Bentonite was used for preparing tablets after granulation. The prepared tablets were tested for their pharmacopeial requirements Further, a high-performance liquid chromatography (HPLC) method was developed to assess the release pattern of alogliptin from the tablets. Besides, differential scanning calorimetry (DSC), fourier transform infrared spectroscopy (FTIR), and powder X-ray diffraction (XRD) were used for evaluating the compatibility the drugs and bentonite. Finally, the release from the tablets was tested using the paddle apparatus.

Results: The FTIR and DSC did not show any interaction between the drug and the excipient in contrast to the powder-XRD pattern, which showed a shift for montmorillonite crystal peak. This shift was interpreted by increasing in the spacing of the crystalline structure of montmorillonite. However, the results of pharmacopeial tests showed that the prepared tablets comply with the compendial requirements, In addition, the release profiles of these tablets with aid of hydroxypropyl methylcellulose (HPMC) as a binder revealed a sustained release of alogliptin. Furthermore, the fitting of release data showed that the release from these tablets followed Fickian diffusion that alogliptin released by diffusion from bentonite gel matrix.
\end{abstract}

Conclusion: Bentonite was successfully used for producing sustained-release tablets of alogliptin. However, maintaining the crystal structure of montmorillonite was essential for building the gel structure of bentonite and releasing the drug in a controlled manner.

Keywords: Bentonite, Alogliptin, Sustained-release, Montmorillonite

(C) 2021 The Authors. Published by Innovare Academic Sciences Pvt Ltd. This is an open access article under the CC BY license (https://creativecommons.org/licenses/by/4.0/) DOI: https://dx.doi.org/10.22159/ijap.2021v13i3.40664. Journal homepage: https://innovareacademics.in/journals/index.php/ijap

\section{INTRODUCTION}

Alogliptin gained approval for the first time in 2010 in Japan for the treatment of type 2 diabetes mellitus (T2DM). It is a short-acting dipeptidyl peptidase-4 (DPP-4) inhibitor that works by inhibiting the DPP-4 enzyme to extend the plasma level of glucagon-like peptide-1 (GLP-1) [1]. Alogliptin benzoate has a short half-life of 1-2 $\mathrm{h}$; therefore, it can be given twice a day [2]

The oral route of drug delivery is the most convenient. On the other hand, it has few limitations such as poor patient compliance related to oral side effects; probabilities of dose missing, plasma level fluctuations by multiple drug regimen, which increases the incidence of side effects as well as the overall cost of treatment $[3,4]$. However, these inconveniences can be resolved either by derivatization of the drugs to obtain new drugs with a longer halflife and large therapeutic indices or by formulating modified release and targeted dosage forms for existing drugs $[3,5]$. The first strategy has several difficulties whereas the second is used broadly [6]. However, for the good candidate drugs to be formulated into modified release dosage form, they should be easily absorbed from the GIT (Gastro-Intestinal Tract) and have short half-lives [7].

There are three main terms used for modified release drug delivery systems: sustained-release tablets, delayed-release tablets, and pulsatile-release tablets. Sustained-release or extended-release dosage forms are defined as a dosage form that slows the release rate of a drug [8-10].

The European Pharmacopoeia (2002) recognized bentonite as a naturally occurring mineral clay consisting mainly of montmorillonite which is alkaline aluminum silicate $\mathrm{Al}_{2} \mathrm{O}_{3} .4 \mathrm{SiO}_{2}$. $\mathrm{H}_{2} \mathrm{O}$ and can be swollen with a little water forming a pliable mass [11]. Wet silicate is not absorbed in systemic circulation; so, bentonite is safe for oral delivery. Furthermore, the American food and drug administration did not put a restriction for its use in foodstuffs (CFR-Code of Federal Regulations Title 21, Part 184) [12]. Due to the reactivity of montmorillonite, bentonite has been used as an adsorbent for toxic materials. Its negative charge allows it to bind cadmium, lead, and other toxins. Bentonite is very alkaline, which helps to neutralize the acid in the stomach $[13,14]$.

However, very few papers reported on using bentonite as an excipient for formulating tablets. Bai et al. 2010 reported the use of bentonite as a disintegrating agent [15]. Moreover, Lin et al., 2002 intercalated 5 fluorouracil into montmorillonite to produce a composite of 5 fluorouracil/montmorillonite to treat colorectal cancer [16]. Ranitidine in a study was intercalated with montmorillonite by ion exchange process; then the resulted particles were coated with Eudragit. Ranitidine was released from these particles in a controlled manner [17]. Bounabi et al. intercalated 2hydroxyethyl methacrylate monomer into the interlayer spaces of sodium montmorillonite (MMT) nanoparticles [18]. Further, Olivera and his research group integrated olanzapine into montmorillonite (MMT) in a combination of alginate and xanthan gum biopolymers to improve the formulation of bionanocomposites [19]. Finally, recently, Alkrad et al. investigated the use of bentonite as an excipient in preparing sustained release tablets by direct compression [20]. However, the powder had a poor flowability which limits the use of bentonite as an excipient by direct compression [21,22].

This present study aims to develop a new formula for preparing sustained release alogliptin tablets using bentonite after granulation.

\section{MATERIALS AND METHODS}

\section{Materials}

Alogliptin benzoate was generously gifted from the United Pharmaceutical Industry (Amman, Jordan). Sodium sulfate (anhydrous) and bentonite were purchased from Sigma-Aldrich (Steinheim, Germany). Sodium hydroxide and potassium dihydro phosphate $\left(\mathrm{KH}_{2} \mathrm{PO}_{4}\right)$ were all purchased from Merck (Darmstadt, Germany). Acetonitrile HPLC grade was purchased from MACRON (China). Hydroxypropyl methylcellulose (HPMC) was purchased from 
Yangzhou WeiKem Chemical Co., Ltd (China). Ortho-phosphoric acid was purchase from Frutarom (bekuhaimstalar, UK). Microcrystalline cellulose (Avecil ${ }^{\circledR 101)}$ was purchased from FMC (Brussels, Belgium).

\section{Methods}

\section{Granulation and tableting}

Bentonite (B) and alogliptin benzoate $(\mathrm{AB})$ were sieved separately through a $45 \mu$ sieve. AB, B, and a binder were mixed thoroughly using a pestle and mortar for batch size $10 \mathrm{~g}$. The amount of each component was calculated for preparing $400 \mathrm{mg}$ tablets (table 1). The tablets were prepared from granules prepared either by wet or dry granulation. The sieved granules were mixed with $1 \%$ magnesium stearate before being manually compressed in an $8 \mathrm{~mm}$ die of a single press machine-model AR 400E made by Erweka (Heusenstamm, Germany).

Wet granulation: Water was sprayed over the powder mix then the wet mass was forced through stainless steel sieve $(\varnothing 200 \mathrm{~mm}$, rim size $50 \mathrm{~mm}$ ) with aperture size $0.355 \mathrm{~mm}$. Then, the formed granules were transferred into an oven and, then, they were dried overnight in an oven at $56^{\circ} \mathrm{C}$.

Dry granulation: large tablets (die size 18) (slugs) were prepared from a mixture of alogliptin and Avicel ${ }^{\circledR} 101$ (microcrystalline cellulose (MCC)). The large tablets were milled in a pestle and mortar then sieved using a sieve with an aperture size of $0.355 \mathrm{~mm}[22,24]$.

Table 1: Composition of formulated tablets

\begin{tabular}{llllll}
\hline Formulation & AB (mg) & Bentonite (mg) & Binder (mg) & Lubricant 1\% (mg) \\
\hline HPMC5\% & 25 & 351 & 20 & 4 & Total amount (mg) \\
HPMC10\% & 25 & 331 & 40 & 4 & 400 \\
HPMC20\% & 25 & 291 & 80 & 4 & 400 \\
HPMC30\% & 25 & 251 & 120 & 4 & 400 \\
Avecil10\% & 25 & 331 & 40 & 4 & 400 \\
PEG4000 5\% & 25 & 351 & 20 & 4 & 400 \\
\hline
\end{tabular}

\section{Spectroscopy-measurements}

Differential scanning calorimeter (DSC), Fourier transform infrared spectroscopy (FTIR), and X-ray diffraction (XRD) were used frequently in research to detect any interaction between the drug and the excipients [24-26].

\section{Differential scanning calorimeter (DSC) measurements}

The DSC thermograms of pure alogliptin, HPMC, a physical mixture of milled alogliptin with bentonite and milled granules composed of bentonite, alogliptin, and 20\% HPMC were recorded using a differential scanning calorimeter (model 204 F1 phoenix) made by Netzsch-Gerätebau GmbH, Postfach in Germany. The thermograms were measured between 25 and $300{ }^{\circ} \mathrm{C}$ at a heating rate of 10 ${ }^{\circ} \mathrm{C} / \mathrm{min}$ under a dry nitrogen flow of $20 \mathrm{ml} / \mathrm{min}$. The DSC thermograms were recorded in triplicate. DSC calibration for the instrument was done, using indium $(10 \mathrm{mg}, 99.999 \%$ pure, melting point $156.60^{\circ} \mathrm{C}$, the heat of fusion $28.40 \mathrm{~J} / \mathrm{g}$ ).

\section{Fourier transform infrared spectroscopy (FTIR) measurements}

FT-IR spectrometer (PerkinElmer UATR Two, Li600301 spectrum made in Llantrisant, UK) was used to test the compatibility between the alogliptin and bentonite. The spectra for each of bentonite, alogliptin, HPMC and alogliptin, bentonite, and 20\%HPMC granules were measured between 450 and $4000 \mathrm{~cm}^{-1}$.

\section{$\mathrm{X}$-ray diffraction (XRD) characterization}

The X-ray diffraction (XRD) patterns of bentonite, a mixture of alogliptin and bentonite, and granules of alogliptin, bentonite, and HPMC (20\%) were obtained by a Shimadzu XRD-7000 diffractometer equipped with graphic monochromator $\mathrm{CuK} \alpha$ radiation and a fixed power source $(40 \mathrm{KW}, 30 \mathrm{~mA})$. The scan rate was $0.5^{\circ}(2 \theta) \min ^{1}$.

\section{Flowability measurement}

A volume of $10 \mathrm{~g}$ of each powder was filled in a $25 \mathrm{ml}$ measuring cylinder that was tapped 15 times or until there was no change in the powder volume [23]. The CARR's index (CI) and Hausner Ratio (HR) indicators were estimated according to the following equations (Eq. 1 and 2) [24-26]:

$$
\begin{gathered}
C I=\frac{\text { Tapped density }- \text { Bulk density }}{\text { Tapped density }} * 100 \\
\text { Hausner Ratio }=\frac{\text { Tapped density }}{\text { Bulk density }}
\end{gathered}
$$

\section{Measuring of the friability}

The friability test was performed according to the USP34 [23]. Briefly, 10 tablets were weighed and put in the Friabilator (Erweka
TAR20, Heusenstamm, Germany). The device was turned on at 25 rpm for 4 min. After tumbling, the tablets were removed, de-dusted, and reweighed accurately. The difference ratio was calculated by using the following equation (Eq. 3) [24-25].

$$
\% \text { Friability }=\frac{W I-W F}{W I} * 100
$$

Where WI is the initial weight of the tablets and the WF is their weight after the friability test.

\section{Hardness measurement}

The hardness of ten tablets was measured by using Erweka TBH30 (Germany)

\section{Dissolution profile}

Dissolution profiles over $24 \mathrm{~h}$ were established with aid of a USPII dissolution tester (Hanson Research SR6). The apparatus was run at a rotation rate of $50 \mathrm{rpm}$ and $37^{\circ} \mathrm{C}$. The dissolution test was evaluated in $900 \mathrm{ml}$ potassium dihydrogen phosphate buffers at $\mathrm{pH} 6.7$ [23]. Samples with volume of $2 \mathrm{ml}$ were removed after 1, 2, 3, 4, 5, 6, 7, and $24 \mathrm{~h}$ of starting the test. The Samples were filtered using a $0.45 \mu$ filter before being assayed by using the developed HPLC method.

\section{High-pressure liquid chromatogram (HPLC) assay}

A Thermo Scientific Chromatographic system (Dionex Ultimate 3000-model) connected with a diode array detector (Germany) was used for quantifying alogliptin. A mobile phase consisting of a sodium sulfate anhydrous with ortho-phosphoric acid buffer $\mathrm{pH} 2.3$ [23] and acetonitrile (200:800) at a flow rate of $1.5 \mathrm{ml} / \mathrm{min}$ with a total runtime of $13 \mathrm{~min}$ was used to separate the samples in a C18 column system $(250 \times 4.6 \mathrm{~mm})$, supplied by Thermo scientific. The injection volume for alogliptin benzoate was $100 \mu$ land the detection was carried out at a wavelength of $254 \mathrm{~nm}$.

\section{Statistical evaluation}

The tests were triplicated then the means and standard deviations were calculated. The similarity of the results was tested by t-test with a confidence interval of $95 \%(\mathrm{P}<0.05)$ using (Origin60 $®$ lab program).

\section{RESULTS}

\section{Flowability of granules}

Before and after tapping the different dry granules and the physical mixture of alogliptin and bentonite, the bulk densities were measured using a measuring cylinder. The measuring cylinder was tapped enough over a horizontal surface until no change of the powder volume was observed; the tapped density, then, was calculated. Out of the bulk density and tapped density, each of CARR's and Hausner indexes was estimated, as shown in table 2 below: 
Table 2: The estimated flowability by CARR's index and hausner ratio

\begin{tabular}{llll}
\hline Formulations & Bulk density $(\mathbf{g} / \mathbf{m l})$ & Tapped density $(\mathbf{g} / \mathbf{m l})$ & CARR's index (\%) \\
\hline Alogliptin and Bentonite mixture & $0.43 \pm 0.003$ & $0.71 \pm 0.005$ & $36.3 \pm 0.26$ \\
HPMC5\% & $0.44 \pm 0.003$ & $0.51 \pm 0.004$ & $14.81 \pm 1.17$ \\
HPMC10\% & $0.45 \pm 0.003$ & $0.54 \pm 0.004$ & $16.63 \pm 1.20$ \\
HPMC20\% & $0.53 \pm 0.004$ & $0.64 \pm 0.005$ & $16.61 . \pm 1.19$ \\
HPMC30\% & $0.44 \pm 0.003$ & $0.52 \pm 0.004$ & $1.17 \pm 0.11$ \\
AVICEL10\% & $0.45 \pm 0.003$ & $0.55 \pm 0.004$ & $21.05 \pm 1.17$ \\
PEG 4000 & $0.42 \pm 0.003$ & $0.6 \pm 0.004$ & $29.99 \pm 1.43$ \\
\hline
\end{tabular}

mean $\pm \mathrm{SD}, \mathrm{n}=3$

Table 3: The hardness and friability of prepared tablets

\begin{tabular}{lll}
\hline Formulation & Hardness (N) & Friability (\%) \\
\hline HPMC5\% & $135 \pm 7.071$ & $0.42 \pm 0.02$ \\
HPMC10\% & $115.5 \pm 6.363$ & $0.14 \pm 0.01$ \\
HPMC20\% & $142.5 \pm 17.677$ & $0.66 \pm 0.04$ \\
HPMC30\% & $280 \pm 14.142$ & $1.97 \pm 0.11$ \\
\hline
\end{tabular}

mean $\pm \mathrm{SD}, \mathrm{n}=3$

The results in table 2 show that the non-granulated physical mixture of alogliptin and bentonite had a poor flowability. However, the flowability was improved after granulation.

\section{Hardness and friability of the tablets}

The friability and hardness of the prepared tablets were evaluated. The calculated mean values and standard deviations are presented in table 3 .

The results of friability revealed that the tablets passed the pharmacopeial requirements except for HPMC30\%, which showed a higher friability. Meanwhile, the tablets complied with a test of uniformity of mass; no tablet deviates from $5 \%$ of an average mass of 20 tablets $(398 \pm 4.1)$ which were weighed individually. Furthermore, the hardness of tablets was relatively high; this reflects a high mechanical strength. However, the hardness decreased when the concentration of HPMC increased from 5 to $10 \%$, then increased again when the concentration was increased from 10 to 20 then $30 \%$. On the other hand, the friability decreased with the increase of HPMC content.

\section{FTIR-measurements}

The measured spectra of each of alogliptin (fig. 1), HPMC, bentonite, and prepared granules from the previous mix (with HPMC 20\%) are represented in fig. 2 below. FTIR-spectrum of the bentonite powder showed a band at $1021 \mathrm{~cm}^{-1}$ which is related to the stretch vibrations of $\mathrm{Si}-\mathrm{O}$ in the $\mathrm{Si}-\mathrm{O}-\mathrm{Si}$ groups of the tetrahedral sheet. Besides, the bands at 524 and $464 \mathrm{~cm}^{-1}$ are caused by Si-O-Al (octahedral sheet) and Si-O-Si bending vibrations [23-25].
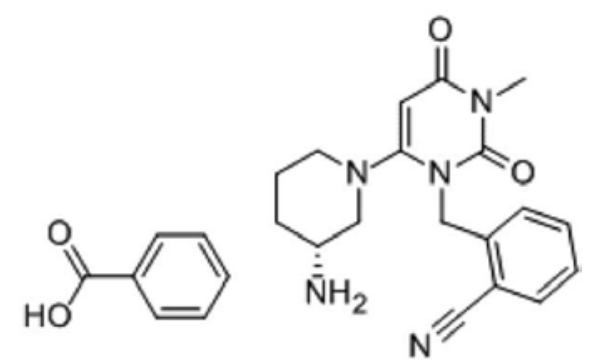

Fig. 1: Structure of alogliptin benzoate

The alogliptin bands of the spectrum did not appear in the spectrum of the granules, which showed only the bands of bentonite. However, the spectrum of bentonite did not change after granulation, which indicates that the drug did not interacts with bentonite. Furthermore, the assignment of the different bands of bentonite and alogliptin are tabulated in table 4 [27-29].

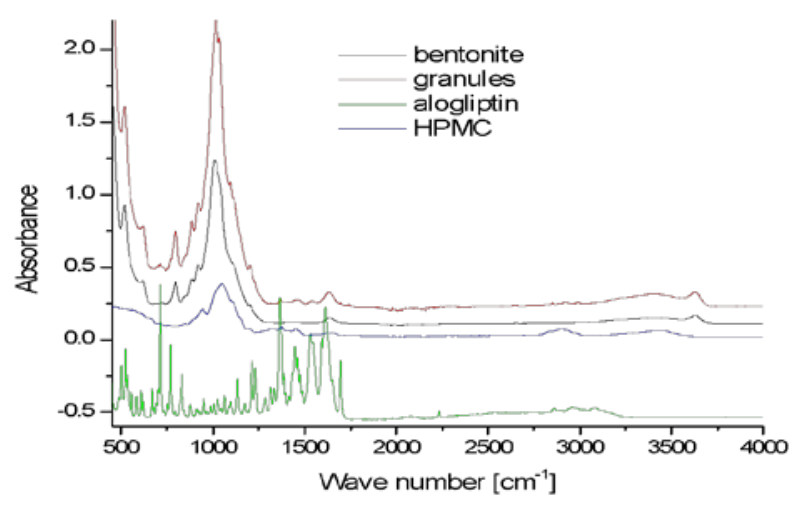

Fig. 2: FTIR-spectra of each of alogliptin, hydroxypropyl methylcellulose (HPMC), bentonite, and the prepared granules of previous components

Table 4: Some bands of FTIR spectrum of alogliptin and possible related groups

\begin{tabular}{ll}
\hline Wavenumber $\mathbf{( \mathbf { c m } ^ { - 1 } )}$ & Bond \\
\hline 3356 & $\mathrm{~N}-\mathrm{H}$ stretching \\
2977 & O-H of carboxylic acid stretching \\
1630 & $\mathrm{~N}-\mathrm{H}$ bending \\
1599 & Carbonyl in the purine ring \\
1451 & $\mathrm{C}-\mathrm{H}$ bending \\
1365 & $\mathrm{C}-\mathrm{N}$ stretching of the aromatic ring \\
1240 & $\mathrm{C}-\mathrm{N}$ stretching of the amine group \\
1521 & $\mathrm{C}=\mathrm{C}$ stretching \\
1623 & $\mathrm{C}=\mathrm{O}$ stretching \\
718 & $\mathrm{C}-\mathrm{H}$ bending \\
\hline
\end{tabular}

The bands of alogliptin did not appear clearly in the granules that the content of alogliptin in the mixture is very low.

\section{DSC measurements}

The DSC thermograms were taken to identify any possible interaction between alogliptin and bentonite. The measured thermograms are represented in fig. 3. 


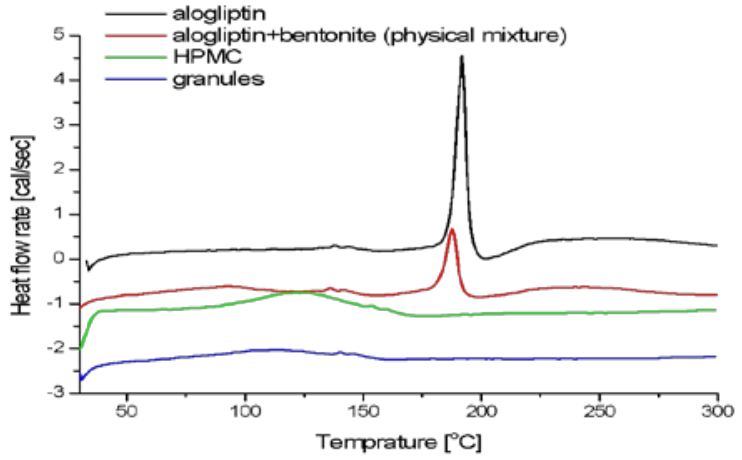

Fig. 3: DSC-thermograms of alogliptin, alogliptin, and bentonite physical mixture, HPMC, and prepared granules of alogliptin with aid of HPMC (20\%). Conditions: samples heated from 30 to $210{ }^{\circ} \mathrm{C}$; heating rate: $10^{\circ} \mathrm{C} / \mathrm{min}$

However, the thermogram of alogliptin in the physical mixture of alogliptin and bentonite did not show any change in comparison to the thermogram of pure alogliptin. Hence, there is no interaction between bentonite and alogliptin. Moreover, the peak of alogliptin did not appears in the thermogram of the granules, which may be related to the low content of the drug.

\section{Powder-XRD-measurements}

Pure bentonite, milled bentonite, alogliptin granules, and milled bentonite, alogliptin, and HPMC granule were scanned within the range of 2-110 deg at a speed of $2 \theta / \mathrm{min}$. The XRD patterns of the samples are given in fig. 4. The XRD pattern of bentonite showed that bentonite contains mainly montmorillonite (Si3.74 Al2.03 $\mathrm{Fe} 0.03 \mathrm{Mg} 0.02$ • 011) [30-32]. Other minerals were found to be quartz, cristobalite albite. However, the XRD pattern of the mixture of bentonite and alogliptin showed a clear change in the first montmorillonite peak.

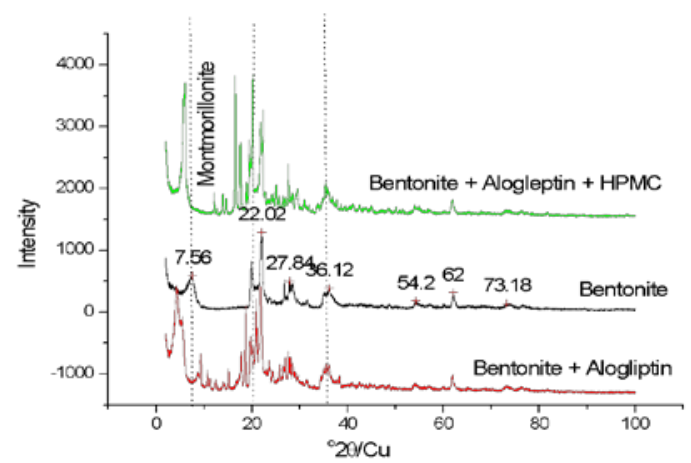

Fig. 4: XRD patterns of bentonite, bentonite-alogliptin granules and bentonite-alogliptin-HPMCmixture (granules with HPMC(20\%))

\section{HPLC-method}

Alogliptin showed a retention time of $5.29 \pm 0.1$ by HPLC-method (fig. 5). A calibration curve was plotted for concentrations between 0.01 and $0.1 \mathrm{mg} / \mathrm{ml}$ using HPLC (fig. 5) to estimate the released drug in dissolution tester and plotting the release profile. The equation of calibration line equation was $y=458 x+0.6$ with a correlation coefficient (r) of 0.99963 . According to the European pharmacopeia the ratio of the height of the peak of the lowest quantifiable amount (LOQ) to the high of noise signal should be higher than 9. The high ratio of the lowest concentration $(0.01 \mathrm{mg} / \mathrm{ml})$ to the noise was much higher than 9 , which means that the detection limit is much lower than $0.01 \mathrm{mg} / \mathrm{ml}$ [11].

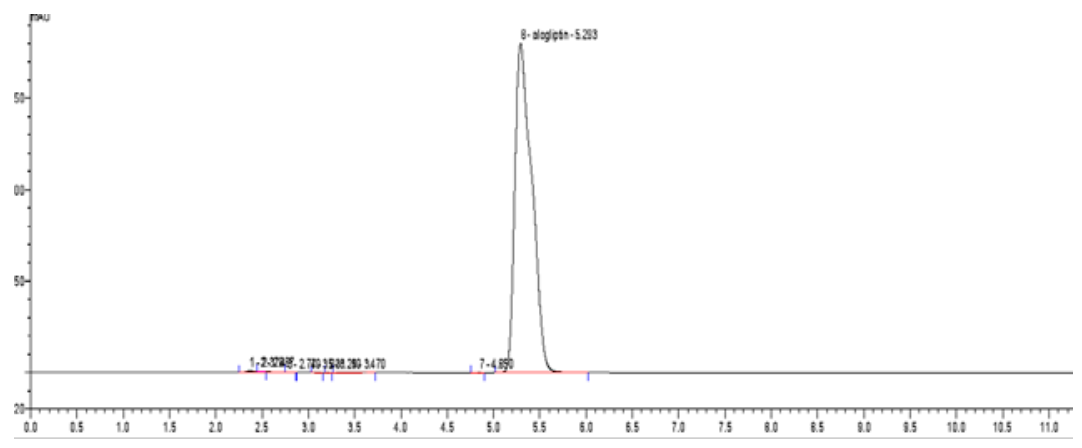

Fig. 5: Chromatogram of Alogliptin Using HPLC-method

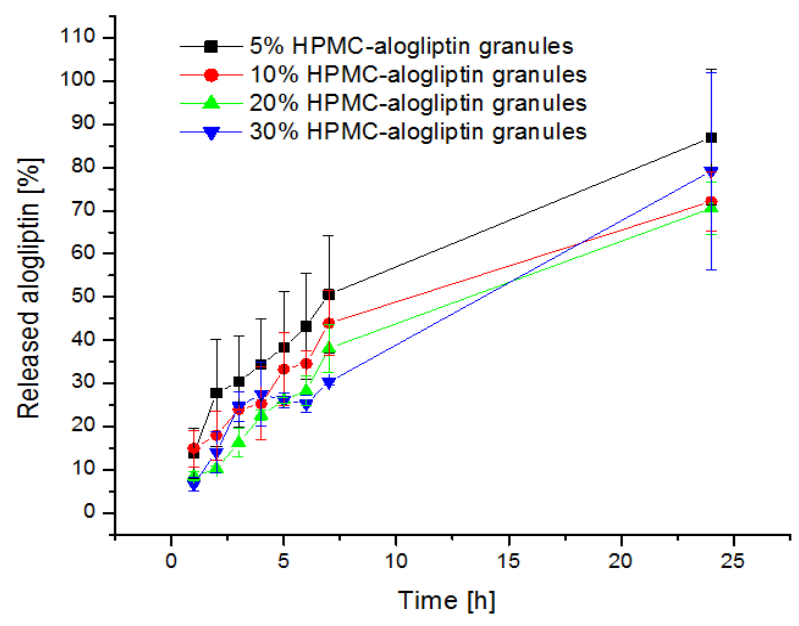

Fig. 6: Dissolution profiles of alogliptin from $5,10,20$ and $30 \%$ HPMC bentonite tablet (mean \pm SD, $n=3$ ) 


\section{The dissolution rate of alogliptin from the tablets}

Many formulations were developed using different binders such as microcrystalline cellulose, PEG4000, starch, and hydroxypropyl methylcellulose (HPMC). The prepared tablets disintegrated rapidly except prepared tablets with aid of HPMC. The content of HPMC was increased gradually to detect the effect of HPMC on the dissolution rate of the drug from the tablets.

The removed samples from the dissolution medium were analyzed using HPLC-method. The cumulative percentage released amounts against time graphs were plotted to establish the release profiles for a period of 24 h. (fig. 6).

Fig. 6 shows that the release rate decreased with increasing HPMC content from 5 to $20 \%$ and increased when the content was $30 \%$. For estimating the release model which the drug follows, the correlation coefficient (r) of cumulative percentage release amount of alogliptin against the time and the square route were estimated for 7 and $24 \mathrm{~h}$. using Origin60 ${ }^{\circledR}$ program; the results tabulated in table 5 .

Table 5: Calculated correlation coefficients for release data

\begin{tabular}{llllll}
\hline Formulation & \multicolumn{2}{l}{ Zero-order 7h } & Zero-order 24h & \multicolumn{2}{c}{ Fickian 24h } \\
\cline { 2 - 6 } & R & SD \% & R & SD \% & R \\
\hline HPMC5\% & 0.979 & 0.307 & 0.938 & 0.711 & 0.993 \\
HPMC10\% & 0.985 & 0.404 & 0.967 & 0.904 & 0.993 \\
HPMC20\% & 0.990 & 1.353 & 0.953 & 2.842 & 0.234 \\
HPMC30\% & 0.966 & 1.620 & 0.966 & 1.495 & 0.427 \\
\end{tabular}

The correlation coefficient for the fitted data was higher for the $7 \mathrm{~h}$. in comparison to $24 \mathrm{~h}$ in the case of the zero-order release model. However, for the Fickian release model in comparison to zero-order, the correlation coefficient was higher. As there are no approved marketed sustained release alogliptin tablets, it was not possible to compare the performance of developed tablets with a reference. Furthermore, as the developed alogliptin tablets using bentonite-free HPMC were disintegrated and did not show a sustained release, it was not possible to estimate a correlation coefficient for these tablets.

\section{DISCUSSION}

Bentonite is not an expensive excipient in comparison to other matrices which are usually used to retard the release of drugs from tablets. The mixture of bentonite and alogliptin has poor flowability, which is the main hindrance of the direct compression [21, 22]. However, by granulation, it was possible to improve the flowability of the mixture [33]. On the other hand, binders are important for building the mechanical strength of granules and tablets [34]. Hence, different binders were used to granulate the mixture of drug and bentonite. The prepared tablets from granules prepared without binder disintegrated rapidly. Further, bentonite did not build a gel structure in dissolution medium when other binders such as Avicel and PEG4000 were used.

DSC and FTIR are used frequently in pre-formulation studies to evaluate any possible interaction in prepared mixtures for preparing tablets [35-36]. FTIR and DSC measurements did not reveal any interaction between bentonite and alogliptin. However, XRD patterns showed a change in the crystalline structure of bentonite when granulated with alogliptin; this explains the disintegration of tablets in the presence of alogliptin. This effect has appeared by shifting the peak of montmorillonite crystal to a lower angle in the XRD pattern of alogliptin and bentonite granules. This may be due to the increase in the spacing of the crystalline structure of montmorillonite which is responsible for building the gel structure of bentonite [19]. The shift was a bit low in the case of granules made of bentonite, alogliptin, and HPMC (20\%). This effect can be attributed to benzoate in alogliptin benzoate structure in a similar way to the reported effect of hydrochloric acid in the dissolution medium or the structure of the drug such as in the case of metformin $\mathrm{HCl}$ on the crystal structure of montmorillonite [20,37]. However, the presence of HPMC could maintain the property of bentonite for building gel structure in an aqueous medium.

However, the other binders could not maintain the gel structure after hydration in the dissolution medium. Hydroxypropyl methylcellulose (HPMC) is a binder as well as one of the most important hydrophilic ingredients for preparing hydrogel matrices [38-40]. Paudel et al. reported that the lowest concentrations for Fickian release for different HPMC grades are 20, 15, and $11 \%$ for K4, K15, and K100, respectively [41]. However, the formulated tablets showed sustained release up to a concentration of HPMC 5\%; hence the sustained release can be related to bentonite, not to HPMC.
The high mechanical strength is useful in preparing sustainedrelease tablets [42]. The prepared tablets showed a high mechanical strength in general. This hardness was increased with increasing HPMC content. The high mechanical strength was not useful for building the gel structure of bentonite in the case of using avecil ${ }^{\circledR}$ and PEG4000 or slowing the release of the drug. There are many strategies for designing sustained-release tablets. Some designs depend on erosion, permeation, or slow dissolution [5]. It is assumed that the sustained release of alogliptin is achieved by diffusion through the matrices not by the erosion, as the tablets swelled, maintained their integrity, did not disintegrate and their volume did not decrease during the dissolution test. This assumption was confirmed by the results of the data fitting of alogliptin release from bentonite and that it follows Fickian diffusion through the matrix $[26,38,33]$.

\section{CONCLUSION}

Bentonite was used successfully in preparing sustained-release tablets containing alogliptin. However, this was possible only with aid of hydroxypropyl methylcellulose (HPMC). Furthermore, this study revealed the effect of benzoate on the crystalline bentonite structure and, as a result, the building gel structure of bentonite in water was hindered. Different used binders did not help to maintain the gel structure except by using HPMC. Increasing the concentration of HPMC didn't improve the linearity of the constant release. Using powder-XRD was possible to detect the change in the crystalline structure of bentonite in the presence of alogliptin benzoate.

\section{FUNDING}

Nil

\section{AUTHORS CONTRIBUTIONS}

All the authors have contributed equally.

\section{CONFLICT OF INTERESTS}

The authors declare no conflicts of interest.

\section{REFERENCES}

1. Teramachi H, Ohta H, Tachi T, Toyoshima M, Mizui T, Goto C, et al. Pharmacoeconomic analysis of DPP-4 inhibitors. Die Pharmazie 2013;68:909-15.

2. Christopher R, Covington P, Davenport M, Fleck P, Mekki QA Wann ER, et al. Pharmacokinetics, pharmacodynamics, and tolerability of single increasing doses of the dipeptidyl peptidase-4 inhibitor alogliptin in healthy male subjects. Clin Ther 2008;30:513-27.

3. Chen X, Wen H, Park K. Challenges and new technologies of oral controlled release. In: Wen H, Park K. editors. Oral controlled release formulation design and drug delivery: Theory to Practice. New Jersey: Wily; 2010. p. 257-77. 
4. Qiu Y, Zhang G, Wise DL. Research and development aspects of oral controlled-release dosage forms. In: L Wise DL. Editor. Handbook of pharmaceutical controlled release technology. New York: Marcel Dekker; 2000. p. 527-30.

5. Agarwal G, Agarwal S, Karar PK, Goyal S. Oral sustained-release tablets: an overview with a special emphasis on matrix tablet. Am J Adv Drug Delivery 2017;5:64-76.

6. Bhowmik D, Bhanot R, Kumar KP. Extended-release drug delivery-an effective way of novel drug delivery system. Res J Pharma Dosage Forms Tech 2018;10:233-44.

7. Zalte HD, Saudagar RB. Review on sustained release matrix tablet. Int J Pharm Biol Sci 2013;3:17-29.

8. Dash TR, Verma P. Matrix tablets: an approach towards oral extended-release drug delivery. Int J Pharm Sci Rev Res 2013;2:12-24.

9. Jaimini M, Kothari AH. Sustained-release matrix-type drug delivery system: a review. Drug Delivery Ther 2012;2:142-8.

10. Patel H, Panchal DR, Patel U, Brahmbhatt T, Suthar M. Matrix type drug delivery system: a review. J Pharm Sci Biosci Res 2011;1:143-51.

11. European council. European Pharmacopoeia. 4th ed. Strasbourg; 2002.

12. CFR-Code of Federal Regulations Title 21, Part 184. Available from:

https://www.accessdata.fda.gov/scripts/cdrh/cfdocs/cfcfr/CF RSearch.cfm?fr=184.1155. [Last accessed on 26 Dec 2020]

13. Ozcan AS, Ozcan A. Adsorption of acid dyes from aqueous solutions onto acid-activated bentonite. J Colloid Interface Sci 2004;276:39-46.

14. Lagaly G. Bentonites: adsorbents of toxic substances. In: Schwuger MJ, Haegel FH. editors. Surfactants and Colloids in the Environment. Darmstadt: Dr. Dietrich Steinkopff Verlag $\mathrm{GmbH}$; 1994. p. 61-72.

15. Bai H, Jiang Y, Xu J. Preparation of ibuprofen dispersible tablets using purified bentonite as the disintegrants. Chinese J Hosp Pharm 2010;5:394-6.

16. Lin FH, Lee YH, Jian CH, Wong JM, Shieh MJ, Wang CY. A study of purified montmorillonite intercalated with 5-fluorouracil as drug carrier. Biomaterials 2002;23:1981-7.

17. Joshi GV, Kevadiya BD, Bajaj HC. Controlled release formulation of ranitidine-containing montmorillonite and Eudragit ${ }^{\circ}$ E-100. Drug Dev Ind Pharm 2010;36:1046-53.

18. Bounabi L, Mokhnachi NB, Haddadine N, Ouazib F, Barille R. Development of poly(2-hydroxyethyl methacrylate)/clay composites as drug delivery systems of paracetamol. J Drug Delivery Sci Tech 2016;33:58-65.

19. Oliveira AS, Alcântara AC, Pergher SB. Bionanocomposite systems based on montmorillonite and biopolymers for the controlled release of olanzapine. Mater Sci Eng C 2017;75:1250-8.

20. Alkrad JA, Shmeis RA, Alshwabkeh I, Abazid H, Mohammad MA. Investigation of the potential application of sodium bentonite as an excipient in formulation of sustained-release tablets. Asian J Pharm Sci 2017;12:259-65.

21. Chen H, Aburub A, Sun CC. Direct compression tablet containing $99 \%$ active ingredient-a tale of spherical crystallization. J Pharm Sci 2019;108:1396-400.

22. Aulton ME. Pharmaceutics: the science of dosage form design. New York: Churchill Livingstone; 2002.

23. United States Pharmacopeia Convention. United States Pharmacopeia and National Formulary (USP 34-NF29). United States Pharmacopeia Convention; 2011.

24. Kothiya OM, Patel BA, Patel KN, Patel MM. Formulation and characterization of sustained release matrix tablets of ivabradine using 32 full factorial design. Int J Appl Pharm 2018;10:59-66.
25. Adedokun M, Onah BE, Attama AN. Physico-mechanical and release properties of sustained-release artesunate tablets in hydroxypropyl methylcellulose matrix. Int J Appl Pharm 2018;10:103-8.

26. Mishra B, Mohanty B. Once-daily immediate and extendedrelease bilayer tablets of etoricoxib: a study on the release kinetics. Int J Appl Pharm 2019;1:230-5.

27. Caglar B, Afsin B, Koksal E, Tabak A, Eren E. Characterization of unye bentonite after treatment with sulfuric acid. Quimica Nova 2013;36:955-9.

28. Caglar B, Afsin B, Tabak A, Eren E. Characterization of the cation-exchanged bentonites by XRPD, ATR, DTA/TG analyses and BET measurement. Chem Eng J 2009;149:242-8.

29. Senturk HB, Ozdes D, Gundogdu A, Duran C, Soylak M. Removal of phenol from aqueous solutions by adsorption onto organomodified tirebolu bentonite: Equilibrium, kinetic and thermodynamic study. J Hazard Mater 2009;172:353-62.

30. Carter JR, Hatcher MT, Di Carlo L. Quantitative analysis of quartz and cristobalite in bentonite clay-based products by Xray diffraction. Anal Chem 1987;59:513-9.

31. Ravindra Reddy T, Kaneko S, Endo T, Lakshmi Reddy S. Spectroscopic characterization of bentonite. Laser Photonics Rev 2017;4:1-4.

32. Arita S. Characterization of bentonite by XRD and SEM-EDS and use to increase $\mathrm{pH}$ and color removal, $\mathrm{Fe}$ and organic substances in peat water. J Clean Energy Technol 2013;1:313-7.

33. Schiano S, Chen $\mathrm{L}, \mathrm{Wu} \mathrm{CY}$. The effect of dry granulation on flow behaviour of pharmaceutical powders during die filling. Powder Technol 2018;337:78-83.

34. Cantor SL, Augsburger LL, Hoag SW, Gerhardt A. Pharmaceutical granulation processes, mechanism and the use of binders. In: Augsburger LL, Hoag SW. editors. Pharmaceutical dosage forms: tablets 3rd ed. London: CRC Press; 2008. p. 261-302.

35. Rojek B, Wesolowski M. DSC supported by factor analysis as a reliable tool for compatibility study in pharmaceutical mixtures. J Therm Anal Calorim 2019;138:4531-9.

36. Pani NR, Nath LK, Acharya S, Bhuniya B. Application of DSC, IST, and FTIR study in the compatibility testing of nateglinide with different pharmaceutical excipients. J Therm Anal Calorim 2012;108:219-26.

37. Bendou S, Amrani M. Effect of hydrochloric acid on the structural of sodic-bentonite clay. J Miner Mater Charact Eng 2014;2:404-13.

38. Siepmann J, Peppas NAA. Modeling of drug release from delivery systems based on hydroxypropyl methylcellulose (HPMC). Adv Drug Delivery Rev 2012;64:163-74.

39. Gharti KP, Budhathoki U, Thapa P, Bhargava A. Formulation in vitro evaluation of floating tablets of hydroxypropyl methylcellulose and polyethylene oxide using ranitidine hydrochloride as a model drug. J Young Pharm 2012;4:201-8.

40. Gurny R, Doelker E, Peppas NA. Modelling of sustained release of water-soluble drugs from porous, hydrophobic polymers. Biomaterials 1982;3:27-32.

41. Paudel P, Noori MH, Poudel BK, Shakya S, Bhatta P, Lamichhane S. Influence of different grades and concentrations of hydroxypropyl methylcellulose on the release of metformin hydrochloride. World J Pharm Sci 2014;2:966-80.

42. Saravanan M, Nataraj KS, Ganesh KS. The effect of tablet formulation and hardness on in vitro release of cephalexin from Eudragit L100 based extended-release tablets. Biol Pharm Bull 2002;25:541-5.

43. Korosa W, Punsalanb D. Polymer glasses: diffusion in. In: Buschow KHJ, Flemings EJ, Kramer EJ, Veyssière P, Cahn RW, Ilschner B, et al. editors. Encyclopedia of materials: science and technology. $2^{\text {nd }}$ ed. Chatillon: Pergamon; 2001. p. 7305-315. 